\title{
Revista Brasileira de Enfermagem REBEn \\ Intervenções de enfermagem durante crises álgicas em portadores de Anemia Falciforme
}

\author{
Nursing interventions for patients with Sickle Cell during pain crisis \\ Intervenciones de enfermería durante las crisis de dolor en portadores de Anemía Falciforme
}

\section{Dária Guedes da Silva}

Aluna do $4^{\circ}$ ano da Faculdade de Enfermagem da Universidade de Santo Amaro, São Paulo, SP.

Isaac Rosa Marques

Enfermeiro. Mestre em Enfermagem. Professor Adjunto da Faculdade de Enfermagem da Universidade de Santo Amaro, São Paulo, SP. Orientador do trabalho.

Trabalho de Conclusão de Curso apresentado em 2006 à Faculdade de Enfermagem da Universidade de Santo Amaro (UNISA).

Submissão: $13 / 03 / 2007$

Aprovação: 25/04/2007

\section{RESUMO}

A anemia falciforme é a doença genética mais comum em nosso país. As complicações por ela geradas resultam em crises dolorosas de difícil controle. Considerando este contexto, o presente artigo tem como objetivo evidenciar quais ações e intervenções podem ser realizadas pela equipe de enfermagem a fim de minimizar a dor nesses pacientes. Foi realizada uma revisão de literatura com pesquisa nas Bases de dados LILACS, BDENF e SciELO. Os achados revelaram que é necessário ao enfermeiro conhecimento dos processos fisiológicos e da dor, bem como os fatores desencadeantes das crises. A atuação do profissional de enfermagem visa afastar esses fatores desencadeantes de crises, a orientação e educação do paciente e focar onde ocorre a dor, aplicando a intervenção necessária a cada situação. Descritores: Anemia Falciforme; Hemoglobinopatias; Anemia; Dor; Cuidados de enfermagem.

\section{ABSTRACT}

Sickle cell is the most common genetic disease in Brazil. Its complications result in out of control painful crisis. In considering this context, this article aimed at evidencing what nursing actions or interventions can be carried out to minimize those patients' pain. A bibliographic research was carried out in LILACS, BDENf and SciELO databases. Findings demonstrated that it is necessary for the nurse to have enough knowledge about physiologic process of pain as well as the crisis' unchained factors. The acting of nursing professional aims to move away those unchaining factors, the orientation and education of the patient and to focus where the pain occurs, applying the necessary intervention to each situation. Descriptors: Sickle cell; Hemoglobinopathies; Anemia; Pain; Nursing care.

\section{RESUMEN}

La anemia falciforme es la más comun enfermedad genética en Brasil. Sus complicaciones resultan en crisis de dolor sin controle. Al considerar esto contexto, esto artículo objectivó evidenciar las acciones e intervenciones de enfermería que pueden minimizar la dolor del paciente. Una revisión bibliográfica fue empleada en las basis de datos bibliográficos LILACS, BEDENF y SCIELO. Los hallazgos han demonstrado que es necesário para el enfermero tener conocimiento suficiente sobre el proceso fisiológico de la dolor así como de los factores desencadeantes de las crisis. La actuación del profesional de enfermería tiene como objectivo afastar los factores desencadeantes, la orientación y educación del paciente y focar en la ocurencia del dolor, aplicando la intervención necesaria a cada situación.

Descriptores: Anemia de células falciformes; Hemoglobinopatías; Anemia; Dolor; Atención de enfermería.

Silva DG, Marques IR. Intervenções de enfermagem durante crises álgicas em portadores de Anemia Falciforme. Rev Bras Enferm 2007 maio-jun; 60(3):327-30.

\section{INTRODUÇÃO}

A anemia falciforme é uma hemoglobinopatia decorrente de uma mutação responsável pela substituição do ácido glutâmico pela valina, resultando em uma hemoglobina com características físico-químicas alteradas ${ }^{(1)}$. Assim sendo, a anemia falciforme caracteriza-se por uma anemia hemolítica crônica grave, que ocorre em pessoas homozigotas para o gene falciforme.

A evolução clínica caracteriza-se por episódios de dor em virtude da oclusão dos pequenos vasos sanguíneos pelas hemácias falciformes ${ }^{(2)}$.

As infecções são as complicações mais freqüentes nos indivíduos com anemia falciforme ${ }^{(2)}$. Estas infecções acometem vias aéreas, sistema ósteo-articular, nervoso, gastrointestinal e genito-urinário. Em todas essas alterações, a dor se mostra presente.

Num enfoque baseado nos cuidados diretos ao paciente, Smeltzer e Bare ${ }^{(3)}$ afirmam que uma das principais metas, na anemia falciforme, é aliviar a dor. Frente a isso, indaga-se sobre quais ações e 
intervenções podem ser realizadas pela equipe de enfermagem a fim de minimizar a dor em pacientes portadores de anemia falciforme.

Considerando a dor uma sensação de tão grande desconforto e de difícil mensuração, que ocorre com freqüência nos portadores de anemia falciforme, e esta ser a doença hereditária de maior prevalência no Brasi( ${ }^{(4)}$, com estimativa de que 1 em cada 400 a 600 crianças negras têm anemia falciforme ${ }^{(5)}$, justifica-se assim o interesse na realização desta pesquisa, a qual futuramente almeja-se, trará benefícios tanto aos portadores como aos seus cuidadores, dentro e fora do âmbito hospitalar.

\section{Características da Doença}

Foi em 1910 que a doença foi descrita pala primeira vez, por Herrick, um médico americano. Nessa época, foi caracterizada como uma anemia hemolítica com alteração morfológica dos eritrócitos que apresentavam a forma de foice ${ }^{(6)}$. Atualmente, a anemia falciforme é definida como uma doença hemolítica congênita, na qual ocorre a troca do ácido glutâmico por valina no $6^{\circ}$ resíduo da cadeia beta da hemoglobina. Essa alteração dá origem a uma hemoglobina anormal, a hemoglobina "S" ( $\mathrm{Hb} \mathrm{s}$ ).

A Hb s tem característica química especial, pela qual a desoxigenação da hemácia causa sua polimerização, alterando a morfologia do glóbulo, ou seja, facilita seu empilhamento em monofilamentos e agregações em cristais alongados, deformando a membrana citoplasmática e, por fim, levando a célula a tomar a forma de foice ${ }^{(7)}$.

A precipitação e formação de longos cristais no interior dos eritrócitos, quando expostos a concentrações muito baixas de oxigênio, resulta em alongamento e estruturação dos eritrócitos na forma de foice, lesão e danos na membrana celular, tornando os eritrócitos frágeis e diminuindo a sua sobrevida (varia de 15 a 25 dias, sendo o normal ter uma sobrevida de 120 dias) $)^{(3,6)}$.

O portador de anemia falciforme mantém-se sempre anêmico, com valores de hemoglobina variando de 6,5 a $10 \mathrm{~g} / \mathrm{dl}^{(3,7,8,9)}$.

O diagnóstico laboratorial é feito através da eletroforese de hemoglobina ${ }^{(2,3,6,7)}$. Como complementação, podem ser realizados 0 hemograma para confirmar o baixo nível de hemoglobina, Prova de Falcização e Curva de Fragilidade.

A eletroforese deve ser realizada nas amostras do sangue do cordão umbilical por ocasião do nascimento, visando a fazer a triagem para doença falciforme em todos os recém-nascidos sob risco ${ }^{(5)}$.

Antes de se discutir o que o enfermeiro pode fazer para intervir na dor do paciente, discutir-se-á o papel deste profissional no controle da dor. 0 enfermeiro ajuda a aliviar a dor administrando as intervenções que aliviam a dor (incluindo tanto o caminho farmacológico quanto o não farmacológico), avaliando a eficácia dessas intervenções, monitorizando os efeitos adversos e servindo como defensor do paciente quando as prescrições são ineficazes no alívio da dor. Além disso, o enfermeiro serve como educador para o paciente e família para torná-los capazes de manejar as intervenções prescritas quando apropriadas ${ }^{(3)}$.

Para tanto, o objetivo deste estudo foi o de reunir um corpo de conhecimentos teóricos sobre o tema, a partir de uma revisão semi-estruturada da literatura.

\section{MÉTODO}

Trata-se de uma revisão bibliográfica semi-estruturada, baseada em consulta às bases de dados bibliográficos LILACS, BDENF e SciELO. A expressão de pesquisa foi constituída pelos unitermos: "anemia falciforme", "anemias", "dor", "hemoglobinopatias" e "enfermagem". Como limites de pesquisa foram estabelecidos: o idioma português e o recorte temporal de 1992 até 2004. Este recorte de tempo foi escolhido devido aos materiais selecionados terem sido publicados em sua grande maioria neste espaço de tempo, e os poucos anteriores ao ano de 1992 não apresentaram dados relevantes para a pesquisa.
A análise do material foi realizada após as leituras analítica e sintética, seguindo-se o fichamento. Em seguida foram estabelecidas categorias temáticas para apresentação, as quais foram divididas da seguinte forma: "Características da doença", "Processo fisiopatológico e Descrições da dor", "Fatores precipitantes" e "Intervenções de enfermagem".

\section{RESULTADOS E DISCUSSÃO}

\subsection{Apresentação da Amostra}

A tabela 1 apresenta o quantitativo dos trabalhos encontrados sobre 0 tema pesquisado. Observa-se que a maioria dos trabalhos foi apresentada na forma de artigo de periódico.

Tabela 1. Classificação do material segundo tipo de publicação. São Paulo, 2006.

\begin{tabular}{lcc}
\hline Tipo de publicação & $\mathbf{n}$ & $\%$ \\
\hline Artigo de periódico & 10 & 71,4 \\
Livros ou capítulos & 4 & 28,6 \\
Tese ou dissertação & - & - \\
Material de congresso & - & - \\
\hline TOTAL & 14 & 100,0 \\
\hline
\end{tabular}

\subsection{Processo Fisiopatológico e Descrições da dor}

A dor pode ser definida como uma experiência subjetiva que pode estar associada a dano real ou potencial nos tecidos, podendo ser descrita tanto em termos desses danos quanto por ambas as características. Independente da aceitação dessa definição, a dor é considerada como uma experiência genuinamente subjetiva e pessoal(12). A dor faz parte de muitas manifestações presentes no portador de anemia falciforme, podendo ser aguda ou crônica ${ }^{(3)}$.

A dor aguda tem geralmente um início recente e é mais comumente associada com uma lesão específica. A dor aguda indica que o dano ou a lesão ocorreu. Esta chama a atenção para o fato que está ocorrendo e ensina a evitar situações dolorosas, potencialmente similares, geralmente diminui à medida que ocorre a cura. A dor crônica é uma dor constante ou intermitente que persiste por certo período de tempo. Ela se prolonga além do tempo previsto para a cura e, freqüentemente, não pode ser atribuída a uma causa específica. Talvez seu inicio não seja bem definido e, geralmente, é difícil tratá-la, pois ela não costuma responder ao tratamento direcionado a sua causa. Apesar de a dor aguda ser um sinal útil de que alguma coisa está errada, a dor crônica geralmente se torna um problema por si só(3).

As crises dolorosas são responsáveis pela maioria dos casos de atendimentos de emergência e hospitalização, assim como pela má qualidade de vida dos pacientes acometidos. Estas crises dolorosas são responsáveis por $60 \%$ dos motivos de internação dos pacientes portadores de anemia falciforme $e^{(1)}$

A dor presente geralmente é isquêmica, com intensidade variável (na maioria dos casos ocorre de forma intensa) de recorrência imprevisível, podendo iniciar-se aos seis meses de idade. O portador de anemia falciforme apresenta dor geralmente devido a episódios de vasoclusão, que ocorrem devido à obstrução dos vasos sanguíneos pelas células falciformes, ocluindo os capilares causando infartos e disfunção dos órgãos acometidos. As crises falciformes são caracterizadas por ataques vasoclusivos agudos, dolorosos e recidivantes, que afetam as extremidades, 0 abdome, 0 tórax e as vértebras ${ }^{(11)}$. Este é 0 tipo de crise mais comum, acomete, com freqüência, o sistema músculo esquelético e tem natureza nociceptiva(8). Os primeiros sinais de vasoclusão são dores abdominais, torácicas, musculares e ósseas. A dor óssea aguda acomete articulações do joelho, ombros, cotovelos e ossos longos como o fêmur e a tíbia.

Em estudo realizado no qual os portadores de anemia falciforme foram indagados sobre episódios de dor, revelou que para a totalidade da amostra, a crise de dor manifestava-se atacando, inicialmente, a região óssea, como articulações, o abdome e parte inferior das $\operatorname{costas}^{(9)}$. 


\subsection{Fatores Precipitantes}

A oclusão microvascular resulta em crises dolorosas agudas, enquanto a oclusão macrovascular parece ser a causa da falência de órgãos ${ }^{(8)}$.

As infecções são complicações mais freqüentes nos indivíduos com anemia falciforme. Essas infecções, acompanhadas de acidose, hipóxia e desidratação, podem desencadear e/ou intensificar as crises de falcização, já que favorecem a produção de citocinas inflamatórias, aumentando, assim, a expressão das moléculas de adesão endolteliais e a adesão das células falciformes e dos polimorfonucleares no endotélio vascular ${ }^{(2)}$. Complicações decorrentes de infecções virais e bacterianas, otite média aguda, pneumonias, necrose da medula óssea, meningite, gastroenterite, infecção do trato urinário e septicemias, patologias comuns ao portador de anemia falciforme, geralmente apresentam em seu curso a dor.

As infecções, a desidratação e a hipóxia parecem ser a principal causa de desencadeantes da dor ${ }^{(2,3,7,8)}$, bem como a acidose ${ }^{(2,8,12)}$. Outras condições também citadas com muita freqüência são a exposição a temperaturas frias $^{(2,5,7,8,12)}$, febre ${ }^{(7,12)}$, gravidez ${ }^{(3,11)}$ e o estresse físico e psicológico ${ }^{(3,5,8)}$.

\subsection{Intervenções de Enfermagem}

A atuação do profissional de enfermagem durante as crises álgicas necessita de conhecimento fisiológico do processo da dor. Este tem de estar apto a não somente atuar durante as crises, deve também educar 0 paciente de modo a evitar que as crises de dor ocorram, orientando-os a como evitar e perceber esses sinais.

As intervenções podem ser embasadas também em modelos teóricos como 0 de Roy ${ }^{(9)}$. A construção deste modelo foi baseado na teoria de sistemas. Nele, o ser humano é visto como um sistema adaptativo, constantemente respondendo a estímulos do meio ambiente interno e externo, caracterizados em focais, contextuais e residuais. Estes resultam em quatro modos adaptativos: fisiológico, autoconceito ou identidade grupal, função do papel e interdependência. O objetivo principal de enfermagemé a promoção da adaptação do cliente nestes quatro modos adaptativos.

A enfermeira passa mais tempo com o paciente com dor do que qualquer outro profissional da saúde e tem a oportunidade de ajudar a aliviá-la, assim como seus efeitos nocivos ${ }^{(3)}$. A abordagem do paciente com dor deve começar pela história e exame físico, nos quais se procura o fator desencadeante ou associado ${ }^{(13)}$. A doença falciforme, com todas as suas alterações sanguíneas, propicia ao portador o risco de desenvolver os tipos de crises dolorosas descritas a seguir:

\subsubsection{Intervenções na Crise Vasoclusiva}

É a crise mais comum ${ }^{(5,8)}$ e mais característica da doença, ocorre devido a obstrução dos vasos sanguíneos pelas células falciformes emaranhadas e rígidas, que causam anoxia tissular e possivelmente necrose ${ }^{(5)}$. Surge inesperadamente, e a dor por ela gerada é de intensidade que pode ser de leve a intensa, e a duração pode ser de dias a semanas.

Os sintomas da crise vasoclusiva incluem dor abdominal ${ }^{(2,5,7)}$, devendo então serem descartadas outras patologias como apendicite ou abdome agudo cirúrgico, febre ${ }^{(5,7)}$, dor muscular ou óssea grave ${ }^{(5,7,8,14)}$. Os locais mais freqüentes para o surgimento de dor óssea aguda são a região lombosacra, joelhos, ombros, cotovelos, fêmur e tíbias ${ }^{(14)}$.

A hidratação $0^{(3,5-7,11,12,14)}$, por via oral ou endovenosa, constitui-se no principal cuidado para evitar-se a ocorrência da crise vasoclusiva, bem como a melhora da dor quando o paciente encontra-se em crise. Ahidratação deve ser cautelosa, porque esses pacientes lidam de maneira inadequada com infusões rápidas e podem desenvolver síndrome pulmonar aguda ou edema pulmonar ${ }^{(6)}$

Deve-se estimular a ingestão de líquidos como água, sucos de frutas, sopas e gelatinas. Os líquidos facilitam a hemodiluição e revertem a aglutinação de células falciformes dentro dos pequenos vasos sanguíneos(6). A quantidade de líquido recomendada é de aproximadamente de 2000 a $3000 \mathrm{ml}$ em 24 horas, a hemodiluição dificulta o processo de polimerização, prevenindo assim a falcização(9).

Outros cuidados incluem a administração de analgésicos opióides ${ }^{(3)}$ como a morfina ${ }^{(6)}$, sendo está considerada a droga ideal para dor intensa ${ }^{(13)}$, antiinflamatórios não-esteróides ${ }^{(3)}$, repouso ${ }^{(5,11)}$, promover 0 conforto posicionando cuidadosamente as áreas com dor e aplicando calor úmido no local ${ }^{(3,5,6)}$. Alguns autores sugerem a analgesia controlada pelo paciente (ACP) com sulfato de morfina ${ }^{(3)}$ ou com tramado(l) ${ }^{(1)}$ como a melhor escolha. Desenvolver técnicas que ajudem a diminuir o medo e a ansiedade gerada pela situação devem ser aplicadas constantemente.

Nas terapias com opióides, a suspensão da droga deve ser gradual, para evitar a síndrome de abstinência ${ }^{(13)}$. A equipe de enfermagem deve estar atenta aos efeitos colaterais dessas drogas, que incluem a depressão respiratória, náuseas, vômitos, prurido, reações de hipersensibilidade e constipação intestinal.

A crise vasoclusiva pode acarretar o comprometimento de vísceras como o pulmão, causando a síndrome torácica aguda (STA). Esta pode manifestar-se após dois ou três dias de crise vasoclusiva intensa, assim como complicação de cirurgia ou anestesia geral, podendo evoluir rapidamente para falência respiratória e morte ${ }^{(13)}$. O paciente apresenta dor torácica de vários graus, dispnéia, hipoxemia, febre e prostração(6).

As intervenções de enfermagem baseiam-se na observação constante do paciente, pois esta situação é de início súbito, e possui prognóstico desfavorável. Observar sinais de confusão mental, devido a hipóxia recorrente, monitorização não invasiva, estar atento as doses excessivas de analgésicos que podem agravar a hipoventilação(6), observar a necessidade de oxigenioterapia e administrá-la quando necessário, elevar o decúbito para melhorar a ventilação.Verificar os resultados de gasometria arterial e hemograma; no primeiro identificando baixos níveis de $\mathrm{PaO} 2$ e no segundo neutrofilia que pode indicar infecção(6).

Com relação ao sistema músculo-esquelético, uma das complicações mais freqüentes decorrentes da crise vasoclusiva é a dactilite, conhecida também como "síndrome mão e pé" que geralmente ocorre na infância, na qual as mãos ou pés, ou ambos, tornam-se edemaciados e extremamente dolorosos. Por ser característica na infância, bem como indicativa da primeira crise vasoclusiva, as intervenções da dactilite baseiam-se na orientação dos pais ou cuidadores a observarem edema e dor nas mãos e pés das crianças.

O uso de compressas quentes, mantas térmicas aquecidas e compressas de aquecimento ou cobertores nas áreas dolorosas do corpo podem ser muito úteis, deve-se avaliar o peso do dispositivo usado para aquecer, visando a evitar o agravamento da dor ${ }^{(5)}$.

A incidência de úlceras maleolares recorrentes devido à estase, trombose e infecção secundária, costuma ser um achado bem significativo. Em pesquisa realizada com portadores de anemia falciforme constatou-se que $44 \%$ da amostra utilizada, apresentam ou apresentarão úlceras falciformes no decorrer da vida. A presença destas geralmente é acompanhada de dor crônica, de difícil cicatrização, bem como a predisposição a infecções ${ }^{(12)}$.

As úlceras de perna são de difícil tratamento(6) e sua cicatrização é lenta( ${ }^{(3)}$. Sabe-se que quando as úlceras cicatrizam, o tecido cicatrizado fere-se com facilidade ${ }^{(9)}$. Uma medida profilática constitui-se no cuidado com a região maleolar, promovendo boa circulação, não comprimir a área e estar atento para não provocar traumas nesta região.

No caso de úlceras já existentes, além de repouso, elevação discreta dos membros inferiores, uso de compressas de água morna e curativos diários $^{(7,12)}$, estes devem ser realizados para favorecer o processo de cicatrização, sempre se utilizando técnicas assépticas quando realizar a troca dos curativos ${ }^{(3)}$.

O priaprismo - ereção do pênis que ocorre de forma anormal e extremamente dolorosa, acomete geralmente crianças e adolescentes ou adultos jovens, geralmente manifesta-se nas primeiras horas da manhã ${ }^{(13)}$. Nela, há a obstrução da drenagem venosa do pênis, e se não tratada 
adequadamente leva à fibrose, que pode causar impotência sexual(7,12,13) $e$ esterilidade $^{(7)}$. Além dos sinais e sintomas mencionados, o paciente poderá apresentar também dor no pênis e no períneo, disúria e retenção urinária aguda.

As intervenções neste caso incluem a hidratação $0^{(6,13)}$, banhos mornos, que provocam a vasodilatação, que pode diminuir a dor ${ }^{(3,6,13)}$, orientar 0 paciente a esvaziar a bexiga no início do ataque ${ }^{(3,6)}$. Os pacientes devem ser orientados a procurar atendimento médico, se o priaprismo tiver duração de mais de 3 horas, ou mesmo antes, se houver dor ${ }^{(13)}$. Sem melhora significativa, em 2 a 3 horas com as medidas iniciais, inicia-se a aspiração e irrigação dos corpos cavernosos e eventualmente, transfusões de sangue ${ }^{(6,13)}$.

\subsubsection{Intervenções na Crise de Sequestração Aguda}

Encontrada em crianças com idade entre 8 meses e 2 anos, a crise de sequestração aguda pode provocar o encarceramento maciço e repentino dos eritrócitos no baço e no fígado ${ }^{(5)}$. O baço aumenta de tamanho com dor á palpação, e desenvolve rápido colapso cardiocirculatório ${ }^{(7)}$. 0 paciente apresenta letargia, plaquetopenia e uma queda de hemoglobina que varia em torno de 2 a $3 \mathrm{~g} / \mathrm{dl}$ abaixo do valor basal.

O tratamento consiste em rápida correção da volemia ${ }^{(5-7)}$, administrandose grandes volumes de líquidos orais ou parenterais ${ }^{(5)}$, transfusões de sangue afim de manter o nível de hemoglobina entre 8 e $10 \mathrm{~g} / \mathrm{d} \mid(6,7)$, administração de sedação e analgésicos ${ }^{(5)}$, e controle rigoroso dos sinais vitais ${ }^{(6,7)}$.

\section{CONCLUSÕES}

Como ciência do cuidar, a enfermagem deve estar atenta a propiciar meios que minimizem o desconforto da dor que é gerada pelas complicações decorrentes da anemia falciforme. O conhecimento da patologia e dos fatores desencadeantes das crises devem ser compreendidos pelo enfermeiro e sua equipe de forma que produza efeito positivo, pois esses conhecimentos são essenciais para garantir uma assistência de enfermagem com qualidade a estes pacientes e suas peculiaridades.

A literatura especializada de enfermagem consultada disponibiliza poucos trabalhos com abordagem sobre o tema. Em grande parte do material consultado, percebeu-se que a dor é citada e, portanto, percebida com muita freqüência. Porém, poucos possuem alguma abordagem sobre suas intervenções, e quando citadas, geralmente estão associadas a administração de medicamentos, sendo esta ação apenas uma parte do processo de se diminuir a dor, as intervenções mecânicas são de grande valia no processo de eliminação ou diminuição dessas dores durante as crises álgicas, não devendo ser ignoradas .

A compreensão do processo patológico da dor e dos fatores desencadeantes das crises é de extrema importância para o enfermeiro, pois com este conhecimento o profissional poderá antecipar suas ações, evitando a ocorrência das crises e também intervindo de maneira eficaz diante da ocorrência das mesmas.

\section{REFERÊNCIAS}

1. Lemonica L, Barros GAM, Fujimoto O, Couceiro TCN, Curti I. Analgesia controlada pelo paciente com Tramadol em criança portadora de anemia falciforme. Relato de caso. Rev Bras Anestesiol 1999;49(4):263-5.

2. Nuzzo DVP, Fonseca SF. Anemia falciforme e infecções. J Pediatr 2004; 80(5):347-54.

3. Smeltzer SC, Bare BG. Brunner e Suddarth. Tratado de enfermagem médico-cirúrgica. $8^{a}$ ed. Rio de Janeiro (RJ): Guanabara Koogan; 1998.

4. Silva RBP, Ramalho AS, Cassorla RMS. A anemia falciforme como problema de saúde pública no Brasil. Rev Saúde Pública 1993;27(1):54-8.

5. Boundy J, Clark PG, Copel LM, Falk KM, Gingrich MM, Heflin Cs et al. Enfermagem Médico-Cirúrgica. $3^{a}$ ed. Rio de Janeiro (RJ): Reichman \& Affonso; 2004.

6. Santos GER. Enfermagem no tratamento da anemia falciforme São Paulo (SP): EPU; 1999.

7. César BF. Anemia falciforme. In: Perrone HC, Gutierrez MT, editores. Pediatria - diagnóstico e terapêutica. São Paulo (SP): Robe Editorial; 1998. p. 438-41.

8. Silveira MM, Fonseca LM. A complexa fisiopatologia dos episódios vaso-oclusivos na anemia falciforme. Rev Ciên Farm 2002; 23(1):25-46.

9. Ivo ML, Carvalho EC. Assistência de enfermagem a portadores de anemia falciforme, à luz do referencial de Roy. Rev Latinoam Enfermagem 2003;11(2):192-8.

10. Sousa FAEF. Dor: O quinto sinal vital. Rev Latino-am Enfermagem 2002;10(3):448-7.

11. Branden PS. Enfermagem materno infantil - Enfermagem Prática. $2^{\mathrm{a}}$ ed. Rio de Janeiro (RJ): Reichman \& Affonso; 2000.

12. Andrade MAC, Almeida RCD. Anemia falciforme: cuidados pré, per e pós-operatórios. Arq bras Med 1992:66(3):211-5.

13. Ãngulo IL. Crises falciformes. Medicina 2003;36:427-30.

14. Araújo JT, Comerlatti LKI, Araújo RAT, Bodemeier L. Tratamento da crise de anemia falciforme pela dipirona, hidrocortisona e hidratação. Rev Hosp Clin Fac Med São Paulo 1994;49(1):13-6. 